\title{
The effect of milk-feeding method and hay provision on the development of feeding behavior and non-nutritive oral behavior of dairy calves
}

\author{
K. C. Horvath and E. K. Miller-Cushon ${ }^{1}$ \\ Department of Animal Sciences, University of Florida, PO Box 110910, Gainesville 32611
}

\begin{abstract}
We investigated the interactive effects of common feeding management factors on the development of feeding and non-nutritive oral behaviors in preweaned calves through the weaning transition. Calves were randomly assigned to 1 of 3 treatments that differed by milk-feeding method (teat or bucket) and ad libitum access to chopped timothy hay: control, milk provided by bucket and no access to hay $(\mathrm{CON} ; \mathrm{n}=10)$; milk provided by bucket and access to hay $(\mathrm{H} ; \mathrm{n}=10)$; milk provided via a teat and access to hay $(\mathrm{TH} ; \mathrm{n}=10)$. Calves had ad libitum access to concentrate and water, and were fed $6 \mathrm{~L} / \mathrm{d}$ of pasteurized waste milk, divided into 2 meals. All calves were weaned by removing the second milk meal for $9 \pm 2 \mathrm{~d}$, beginning at $36 \mathrm{~d}$ of age. Daily concentrate and hay intake were recorded, and calves were weighed weekly to measure growth. We recorded the behavior of all calves using $2 \mathrm{~s}$ timelapse video during time periods that encompassed milk meals, from $6000 \mathrm{~h}$ to $1000 \mathrm{~h}$ and $1600 \mathrm{~h}$ to $2000 \mathrm{~h}$, on 2 consecutive focal days in wk 2 and 4 . We continuously monitored lying time and activity using electronic data loggers. During the preweaning period, hay selection by $\mathrm{H}$ and $\mathrm{TH}$ calves was subject to a treatment $\times$ week interaction, with $\mathrm{TH}$ calves increasing hay intake to a greater extent over time. Similarly, we observed a tendency for a treatment $\times$ week interaction for hay dry matter intake. Before weaning, concentrate intake was subject to a treatment $\times$ week interaction, increasing to a greater extent over time for $\mathrm{H}$ and $\mathrm{TH}$ calves, but was greater overall for CON calves. As predicted, milk-feeding method and hay provision influenced the proportion of time devoted to feeding and non-nutritive behaviors. The CON calves spent the greatest amount of time performing non-nutritive sucking directed at the pen, $\mathrm{TH}$ calves the least, and $\mathrm{H}$ calves intermedi-
\end{abstract}

Received October 28, 2016.

Accepted January 9, 2017.

${ }^{1}$ Corresponding author: emillerc@ufl.edu ate amounts. Considering the time $\mathrm{TH}$ calves sucked on their teat when milk was not present in addition to the time they spent sucking on pen fixtures, the total amount of time spent performing sucking behavior was similar between treatments. Although intake was similar across the weaning transition, CON calves had greater average daily gain than $\mathrm{H}$ calves, and $\mathrm{TH}$ calves were intermediate. Providing access to hay and milk via a teat during the milk-feeding stage decreased non-nutritive oral behaviors and influenced feeding behavior.

Key words: dairy calf, feeding behavior, non-nutritive oral behavior

\section{INTRODUCTION}

Providing calves with alternative feeding methods may influence feeding behavior and the development of abnormal behaviors. Non-nutritive oral behaviors, including sucking pen fixtures and cross-sucking, are considered to be detrimental to calf health (Babu et al., 2004) and are more likely to develop in calves not fed by a teat (Hammell et al., 1988). Non-nutritive oral behaviors are a redirection of natural sucking behavior (Jensen and Weary, 2013) and can occur in response to limited food availability (Bokkers and Koene, 2001), among other factors. However, dairy calf management practices can influence the development of feeding behavior (Miller-Cushon and DeVries, 2015).

Calves are typically reared individually on-farm and are often fed milk by bucket, which provides little opportunity to perform the natural sucking behavior (de Passillé, 2001). Sucking behavior is highly motivated, and young ruminants raised separately from their mothers will suck each other and parts of their pen, even when given adequate nutrition (de Passillé, 2001). Additionally, bucket-fed calves have been observed licking more pen fixtures than calves fed by teat (Jensen and Budde, 2006). Understanding the calf's motivation to suck would help us devise feeding and management systems that allow calves to express their natural behaviors, reduce the development of abnormal behaviors, and improve performance (de Passillé, 2001). A rubber 
teat can act as an outlet for sucking behavior, and the action of sucking on the teat elicits the release of hormones involved in digestion (de Passillé, 2001; Lupoli et al., 2001), reduces cross-sucking in group-housed calves (Jung and Lidfors, 2001), and may reduce non-nutritive behaviors in individually housed calves.

Access to forage may also influence the development of non-nutritive oral behavior. Providing hay reduces non-nutritive sucking (Haley et al., 1998) and influences rumen development (Khan et al., 2011b). Access to more water and roughage suppresses cross-sucking in group-housed calves (Bokkers and Koene, 2001). Calves fed only milk will nibble on parts of their stalls as a redirection of their nibbling motivation, but providing concentrate and straw has been shown to reduce non-nutritive nibbling in calves (Veissier et al., 1998). Calves have consistently been observed selecting a proportion of hay in their diet, and this suggests that they are motivated to consume it (Phillips, 2004; MillerCushon et al., 2013b). Providing hay can improve feed efficiency and growth (Coverdale et al., 2004; Castells et al., 2012), as well as the rumen environment (Khan et al., 2011b).

Provision of a teat and access to forage have been found to independently influence feeding behavior and the development of non-nutritive oral behaviors in dairy calves, but it is not clear how these feeding methods may interact to affect calves' behavioral development and performance. This study examined the effects of both hay provision and teat access on the development of feeding patterns, non-nutritive oral behavior, and general calf performance and activity in restriction-fed calves through the milk-feeding stage and across the weaning transition. We hypothesized that hay selection would be influenced by milk-feeding method: calves provided with a teat would direct oral behaviors toward this outlet and select less hay. We also predicted that calves provided with hay or a teat and hay would exhibit fewer non-nutritive oral behaviors than calves fed by bucket with no access to hay, and that a greater cumulative effect would occur in calves provided with both a teat and hay.

\section{MATERIALS AND METHODS}

\section{Animals and Management}

A total of 30 Holstein heifer calves were enrolled at birth at the University of Florida Dairy Unit (Hague, FL). They were fed $4 \mathrm{~L}$ of quality-controlled colostrum and uniquely identified with radiofrequency identification (RFID) ear tags. Calves were housed in individual wire-mesh pens $(0.9 \times 1.8 \mathrm{~m}$, width $\times$ depth $)$ that permitted visual and auditory, but not tactile, contact with other calves for the duration of the experiment. Calves were managed according to the standard operating procedures for this facility. All pens were located in an open-sided barn that protected calves from downward wind and rain. Pens were bedded with sand that was replaced weekly. Calves received $6 \mathrm{~L}$ of pasteurized waste milk mixed with a powdered enhancer (Pasteurized Milk Balancer Protein-Blend, Purina Animal Nutrition LLC, Shoreview, MN) in 2 daily meals, delivered at $0600 \mathrm{~h}$ and $1800 \mathrm{~h}$. Calves had ad libitum access to calf starter (Ampli-Calf STR 20P R50 DBZ9.1 medicated, Purina Animal Nutrition LLC) with supplement (SMI 3.5G AS700 CMB medicated, Purina Animal Nutrition LLC) and water. Calves were disbudded by a University of Florida veterinarian during wk 4 of life using a hot iron. A veterinarian monitored the health of the calves weekly, and calves were healthy for the duration of the experiment. All study procedures were reviewed and approved by the University of Florida Animal Care and Use Committee.

\section{Experimental Design}

At birth, calves were randomly assigned to 1 of 3 treatments that differed by milk-feeding method and access to hay: control ( $\mathbf{C O N} ; \mathrm{n}=10)$, access to hay $(\mathbf{H} ; \mathrm{n}=10)$, and access to milk through a teat and hay $(\mathbf{T H} ; \mathrm{n}=10)$. Calves assigned to the CON treatment were housed using the conventional method for the facility and received milk via a bucket that was placed inside the pen and removed within 5 min after the milk was consumed; concentrate was provided as the sole source of solid feed. Calves assigned to the $\mathrm{H}$ treatment received milk via bucket, ad libitum access to concentrate by bucket, and chopped timothy hay (2 inches) in a bucket separate from the concentrate. Calves assigned to the TH treatment received milk via a rubber teat (Peach Teats; Skellerup Industries, Christchurch, New Zealand): the milk bucket was placed outside the pen and a line was fitted to a 1-way valve connecting the bucket to the teat at the front of the pen. The teat remained in place throughout the day, but the line and bucket were removed within 5 min after the milk meal had been consumed. The TH calves received ad libitum access to chopped timothy hay (2 inches) by bucket, in addition to concentrate. The assigned feeding method continued throughout the milk-feeding stage. All calves were weaned by removing the second milk meal for $9 \pm$ $2 \mathrm{~d}$ (weaning was subject to staff schedule, so it varied slightly in length), beginning in wk 6 . Calves were followed for an additional $10 \mathrm{~d}$ postweaning. Solid-feed rations were maintained throughout the experiment. 


\section{Data Collection}

We weighed and recorded the amount of concentrate and hay consumed daily by subtracting the weight of orts that remained in the morning from the weight of fresh feed provided on the previous day. Remaining concentrate was replaced with fresh concentrate every morning. Hay was replenished daily after the remaining hay from the previous day was weighed, but was fully replaced only once per week. The amount of concentrate and hay provided was increased over time based on the amount of feed each calf consumed, to maintain ad libitum levels of feed. Feed levels were checked in the evening, and calves were given additional concentrate or hay or both when their feed levels were low. Calves were weighed weekly, and BW was used to calculate ADG and feed efficiency (DMI divided by ADG).

To determine the DM of the feed and assess the daily DMI of the calves, we sampled fresh feed and individual orts from each calf each week, just before removal and delivery of fresh feed. Samples taken for DM were oven-dried within $4 \mathrm{~h}$ of collection at $55^{\circ} \mathrm{C}$ for $48 \mathrm{~h}$ to determine DM content. To determine the nutritional profile of solid feed, we sent samples of concentrate and hay to Cumberland Valley Analytical Services Inc. (Hagerstown, MD) for analysis of DM [1358C; method 930.15 (AOAC International, 2000)], ash [5358C; method 942.05 (AOAC International, 2000)], ADF [method 973.18 AOAC International, 2000)], NDF with heat-stable a-amylase and sodium sulfite (Van Soest et al., 1991), and CP $[\mathrm{N} \times 6.25$; method 990.03 (AOAC International, 2000); Leco FP-528 Nitrogen Analyzer, Leco, St. Joseph, MI]. The nutrient content of the solid feed is reported in Table 1.

We recorded the behavior of all calves using $2 \mathrm{~s}$ time-lapse video with a camera (GoPro Her04 silver; GoPro Inc., San Mateo, CA) mounted on a ladder (3.05 m) next to the calf pens being recorded. Calves were

Table 1. Chemical composition of feeds (mean \pm SD, $\%$ of DM unless otherwise noted)

\begin{tabular}{lcr}
\hline $\begin{array}{l}\text { Chemical } \\
\text { composition }^{1}\end{array}$ & Concentrate $^{2}$ & Hay $^{3}$ \\
\hline DM (\%) & $91.25 \pm 0.39$ & $86.65 \pm 2.40$ \\
CP & $22.78 \pm 0.63$ & $6.7 \pm 0.37$ \\
ADF & $16.00 \pm 0.14$ & $40.13 \pm 0.89$ \\
NDF & $28.15 \pm 0.65$ & $61.10 \pm 1.06$ \\
NFC & $40.08 \pm 1.31$ & $23.28 \pm 0.57$ \\
TDN & - & $57.05 \pm 0.40$ \\
\hline
\end{tabular}

${ }^{1}$ Values were obtained from chemical analysis of feed samples.

${ }^{2}$ Pelleted, supplied by Purina Animal Nutrition LLC (Shoreview, MN). Ampli-Calf STR 20P R50 DBZ9.1 (medicated with monensin and diflubenzuron) and supplement SMI 3.5G AS700 CMB (medicated with chlortetracycline and sulfamethazine).

${ }^{3}$ Chopped timothy hay $(5 \mathrm{~cm})$. recorded on 2 consecutive focal days during wk 2 and 2 more consecutive days during wk 4 . Calves were not observed on the day of or the day after disbudding to prevent any potential confounding behaviors related to the procedure. We observed calves from 0600 to $1000 \mathrm{~h}$ and 1600 to $2000 \mathrm{~h}$ to observe individual behaviors in the window encompassing the milk-feeding time, when calves were most active. We reviewed video continuously using Behavioral Observation Research Interactive Software (Friard and Gamba, 2016) to characterize a range of behaviors. We recorded the duration of time spent consuming concentrate and hay (defined as head lowered in feed bucket); licking and consuming nonnutritive materials in the pen (head lowered, mouth movement); sucking on the teat when milk was not present; sucking on other pen fixtures (mouth open with part of buckets or pen sides inside mouth); and grooming (licking or mouth movement directed toward part of body). In addition to non-nutritive sucking directed at the pen, we calculated total non-nutritive sucking time (the combined duration of time spent sucking on the teat, for TH calves, and pen fixtures) and the total duration of all non-nutritive behaviors (pen-directed nonnutritive sucking plus time consuming non-nutritive bedding material). The video data did not allow us to see when bucket-fed calves had finished their milk allotment (and casual live observation indicated that many calves continued to lick their bucket after finishing their meal, with their head lowered obscuring the milk level), so we did not analyze milk-feeding time. However, for teat-fed calves, we were able to observe milk level and determine milk-feeding time, and we used these data to determine the duration of non-nutritive sucking on the teat following the milk meal. We used a total of 5 observers to characterize the behaviors from video (we calculated inter-observer reliability for 1 day of video collection, and reliability $>80 \%$ for all behaviors observed).

To assess general calf activity, we monitored lying time continuously from wk 2 to 5 of life using electronic data loggers (Hobo Pendant G Data Logger; Onset Computer Corp., Pocasset, MA) placed on the rear leg (as validated by Bonk et al., 2013). These data were used to calculate total daily lying time.

\section{Statistical Analysis}

We summarized behavioral data and analyzed them by week (wk 2 and wk 4). First, we analyzed behaviors as the percentage of time spent performing each behavior during the observation period, averaging data between morning and evening observation periods and across consecutive days. We analyzed all behavioral data using the MIXED procedure of SAS (version 9.4; 
SAS Institute Inc., Cary, NC) in a general linear mixed model, with week (wk 2 or wk 4 ) as a repeated measure. The model included the fixed effects of week, treatment, and week $\times$ treatment interaction, and the random effect of calf. We selected compound symmetry as the variance-covariance matrix structure for behavioral data based on best fit, according to Schwarz's Bayesian information criterion. In cases of significant treatment effects, we used the Tukey-Kramer adjustment to test for differences between treatments in individual weeks.

For the milk-feeding stage (data collected during wk 2 to 6 ), we averaged all data measured daily (including total DMI, hay DMI, concentrate DMI, concentrate intake as a percent of total DMI, feed efficiency, BW, ADG, and time spent standing) across each week. We analyzed all data using the MIXED procedure of SAS, treating week as a repeated measure. The model included the fixed effects of week, treatment, and week $\times$ treatment interaction, and the random effect of calf. We selected an autoregressive model as the variancecovariance matrix structure based on best fit, according to Schwarz's Bayesian information criterion.

We also evaluated the effect of weaning on feeding behavior and performance (total DMI, hay DMI, concentrate DMI, concentrate intake as a percentage of total DMI, BW, and ADG). For this analysis, we analyzed a subset of data collected during 3 stages: 10 $\mathrm{d}$ before weaning, weaning $(9 \pm 2 \mathrm{~d})$, and $10 \mathrm{~d}$ postweaning. We averaged data across days within stage. We analyzed data using the MIXED procedure of SAS, with stage (preweaning, weaning, and postweaning) as a repeated measure. The model included the fixed effect of treatment, stage, and treatment $\times$ stage interaction, and the random effect of calf. We selected an autoregressive model as the variance-covariance matrix structure based on best fit, according to Schwarz's Bayesian information criterion. All data were normally distributed. Significance was declared at $P<0.05$, and trends were reported if $0.05<P \leq 0.10$.

\section{RESULTS}

Milk-feeding method and provision of hay influenced concentrate intake and diet selection during the preweaning stage (Table 2). Concentrate DMI was greater overall for CON calves than for $\mathrm{TH}$ calves, and $\mathrm{H}$ calves had intermediate intake. Concentrate intake also tended to be subject to a treatment $\times$ week interaction, with $\mathrm{H}$ calves increasing intake to a greater extent over time than TH and CON calves (Figure 1). We observed no effect of treatment on total feed DMI, or on the growth and feed efficiency of the calves. Selection of concentrate (relative to hay) by $\mathrm{H}$ and $\mathrm{TH}$ calves was subject to a treatment $\times$ week interaction: $\mathrm{TH}$ calves reduced the percentage of concentrate in their diet over time, relative to $\mathrm{H}$ calves (Figure 2a). Similarly, we observed a tendency for a treatment $\times$ week interaction for hay DMI: TH calves increased their hay intake to a greater extent over the milk-feeding stage compared with $\mathrm{H}$ calves (Figure $2 \mathrm{~b}$ ).

As predicted, the milk-feeding method and provision of hay influenced the proportion of time devoted to feeding and non-nutritive behaviors (Table 3). Time spent consuming concentrate was subject to a treatment $\times$ week interaction: $\mathrm{H}$ and $\mathrm{TH}$ calves increased their feeding time to a greater extent between wk 2 and 4 , but the feeding time for CON calves was relatively stable over time. The CON calves also spent more overall time consuming concentrate than calves in the other 2 treatments across both weeks, consistent with treatment differences for concentrate intake. Despite differences in hay intake over time between the $\mathrm{H}$ and $\mathrm{TH}$ treatments, we saw no effect of milk-feeding method on hay feeding time for the $\mathrm{H}$ and $\mathrm{TH}$ calves. The CON

Table 2. Feed intake, BW, ADG, and feed efficiency of calves provided with milk via a bucket and no access to hay (CON), milk via a bucket and access to hay $(\mathrm{H})$, and milk via a teat and access to hay $(\mathrm{TH})$ from wk 2 to 6 during the milk-feeding stage ${ }^{1}$

\begin{tabular}{|c|c|c|c|c|c|c|c|}
\hline \multirow[b]{2}{*}{ Item } & \multicolumn{3}{|c|}{ Treatment } & \multirow[b]{2}{*}{$\mathrm{SE}$} & \multicolumn{3}{|c|}{$P$-value ${ }^{2}$} \\
\hline & $\mathrm{CON}$ & $\mathrm{H}$ & $\mathrm{TH}$ & & $\mathrm{T}$ & $\mathrm{W}$ & $\mathrm{T} \times \mathrm{W}$ \\
\hline Concentrate DMI (kg/d) & $0.234^{\mathrm{a}}$ & $0.161^{\mathrm{ab}}$ & $0.114^{\mathrm{b}}$ & 0.033 & 0.047 & $<0.0001$ & 0.053 \\
\hline Hay DMI (kg/d) & - & 0.023 & 0.027 & 0.003 & 0.428 & $<0.0001$ & 0.057 \\
\hline Concentrate intake ( $\%$ of total DMI) & — & 0.861 & 0.838 & 0.020 & 0.412 & 0.297 & 0.035 \\
\hline $\mathrm{BW}(\mathrm{kg})$ & 52.63 & 51.1 & 51.53 & 1.515 & 0.766 & $<0.0001$ & 0.717 \\
\hline
\end{tabular}

\footnotetext{
$\overline{\mathrm{a}, \mathrm{b}}$ Means within a row with different superscript letters indicate a significant difference $(P<0.05)$ between treatments.

${ }^{1}$ Data are averaged by week.

${ }^{2} \mathrm{~T}=$ treatment $(\mathrm{CON}, \mathrm{H}, \mathrm{TH}) ; \mathrm{W}=$ week on treatment (wk 2-6 of the milk-feeding stage).
} 
Table 3. Behavioral data for calves provided with milk via a bucket and no access to hay (CON), milk via a bucket and access to hay (H), and milk via a teat and access to hay $(\mathrm{TH})$ during the focal weeks (wk 2 and 4 ) of the milk-feeding feeding stage ${ }^{1}$

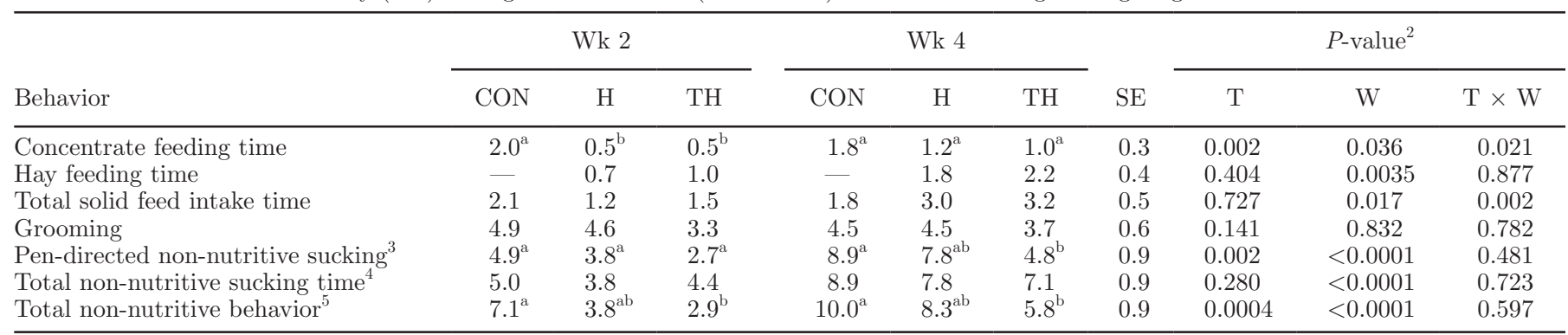

${ }^{\mathrm{a}, \mathrm{b}}$ Means within a row and within a week with different superscript letters indicate a significant difference $(P<0.05)$ between treatments.

${ }^{1}$ All data are reported as the percentage of time spent performing each behavior during the observation period.

${ }^{2} \mathrm{~T}=$ treatment $(\mathrm{CON}, \mathrm{H}, \mathrm{TH}) ; \mathrm{W}=$ week on treatment (wk 2-6 of the milk-feeding stage).

${ }^{3}$ Non-nutritive sucking was sucking directed at pen fixtures, not including the teat, for TH calves.

${ }^{4}$ Time spent sucking directed at pen fixtures, as well as the teat when milk was not present (for TH calves).

${ }^{5}$ Total non-nutritive sucking time plus time spent consuming non-nutritive materials (bedding).

calves were relatively stable in the total amount of time they spent feeding, but both $\mathrm{H}$ and $\mathrm{TH}$ calves increased their total feeding time to a greater extent between wk 2 and 4.

The performance of non-nutritive behaviors was influenced by the provision of hay and a teat (Table 3). Time spent on non-nutritive oral behaviors directed at the pen was subject to an overall treatment effect: CON calves spent more time engaged in non-nutritive sucking than $\mathrm{TH}$ calves, and $\mathrm{H}$ calves spent an intermediate amount of time. The amount of time devoted to this behavior increased between observation weeks (wk 2 and wk 4), with all treatments spending approximately twice as much time sucking pen fixtures in wk

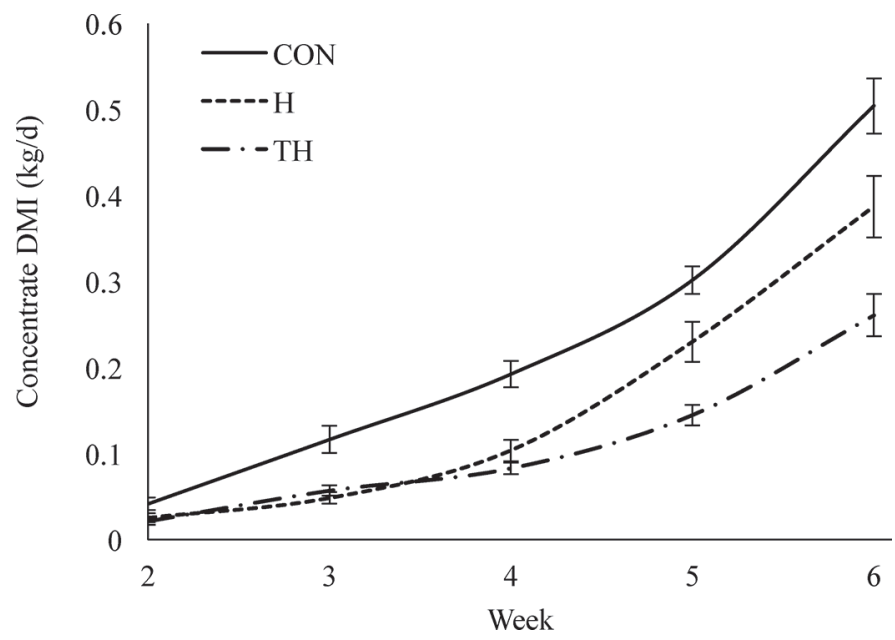

Figure 1. Concentrate DMI of calves provided with milk via a bucket and no access to hay $(\mathrm{CON})$, milk via a bucket and access to hay $(\mathrm{H})$, and milk via a teat and access to hay $(\mathrm{TH})$ from wk 2 to 6 during the milk-feeding stage. Data are averaged across each week. Error bars represent SE.
4 (Table 3). We also assessed total non-nutritive oral behaviors (including pen-directed non-nutritive sucking and time spent licking and consuming bedding material), and similarly found that CON calves spent the
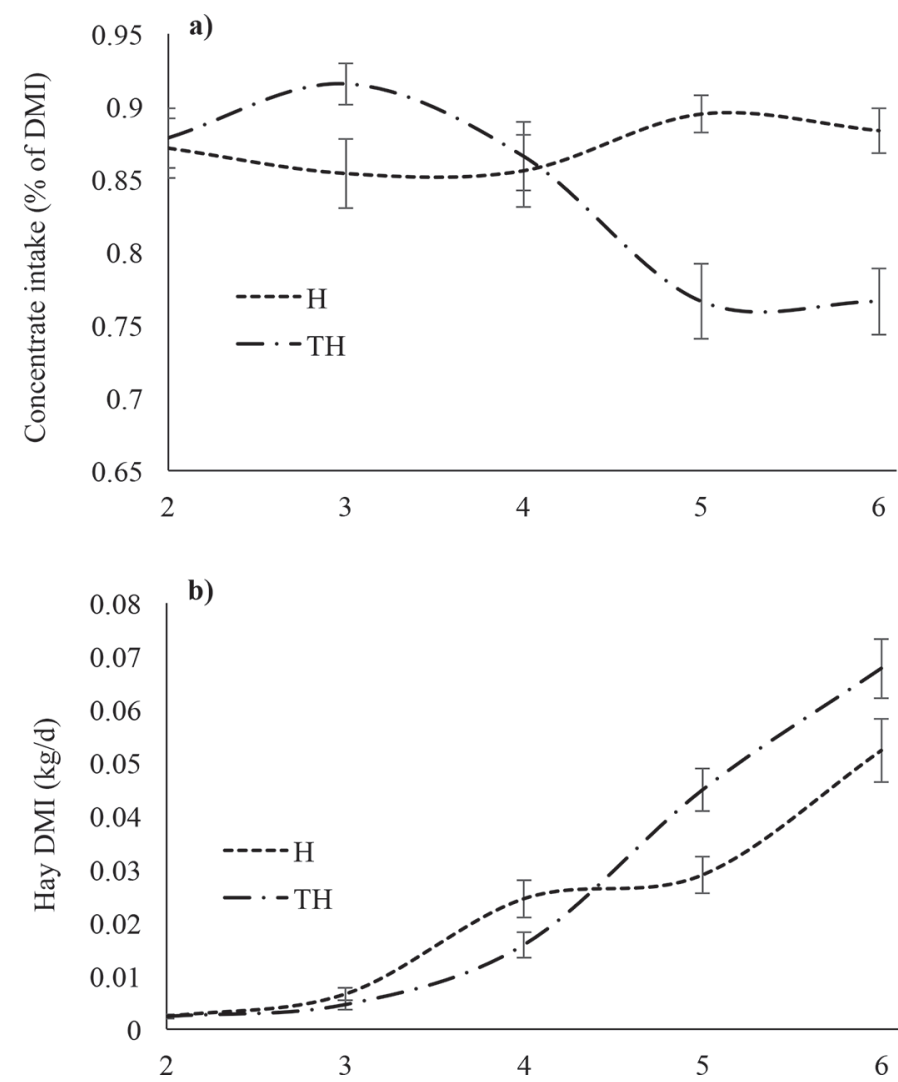

Figure 2. (a) Concentrate intake as a percentage of DMI and (b) hay DMI for calves provided with milk via a bucket and access to hay $(\mathrm{H})$ or milk via a teat and access to hay (TH) from wk 2 to 6 during the milk-feeding stage. Data are averaged across each week. Error bars represent SE. 
most time performing them, followed by $\mathrm{H}$ calves and then TH calves. When considering the amount of time TH calves sucked on their teat when milk was not present, in addition to non-nutritive sucking of pen fixtures, the total amount of time spent on non-nutritive sucking was similar between treatments and increased over time (Table 3). On average, calves spent $4.4 \%$ of the observation period engaged in non-nutritive sucking in wk 2 (approximately 10.6 min per $4 \mathrm{~h}$ observation period) and $7.9 \%$ in wk 4 (approximately $19 \mathrm{~min}$ per $4 \mathrm{~h}$ observation period). We observed no difference between treatments for the amount of time spent grooming, but calves in general spent a considerable amount of time grooming (on average, $4.3 \%$ of observation time, or approximately $10 \mathrm{~min}$ per $4 \mathrm{~h}$ observation period). The overall activity level was similar between calves; there was no difference between treatments in the amount of time spent standing (353.1 vs. 350.2 vs. $365.8 \mathrm{~min} / \mathrm{d}$; $\mathrm{CON}$ vs. $\mathrm{H}$ vs. $\mathrm{TH} ; \mathrm{SE}=18.6 ; P=0.82)$.

When we compared feed intakes and growth parameters across preweaning, weaning, and postweaning, we found that CON calves had consistently greater ADG than $\mathrm{H}$ calves, and $\mathrm{TH}$ calves had intermediate ADG (Table 4). We also observed a tendency for TH calves to consume more hay across all stages of the weaning transition than $\mathrm{H}$ calves. We observed no difference between treatments in the amount of concentrate consumed or total DMI across the weaning transition.

\section{DISCUSSION}

Dairy calves are typically fed restricted amounts of milk by bucket, which reduces their ability to perform natural sucking behavior. One of our predictions was that calves provided with hay or a teat and hay would exhibit reduced non-nutritive oral behaviors compared with calves provided with milk by bucket and no access to hay, and that a greater cumulative effect would occur in calves provided with both a teat and hay. Our results suggest that the provision of a teat and hay during the milk-feeding stage did reduce the development of non- nutritive oral behaviors. Control calves spent the most amount of time engaged in non-nutritive sucking and performing non-nutritive oral behaviors, in agreement with other studies that showed reduced non-nutritive oral behaviors, including both sucking and nibbling, when calves were provided with either hay (Haley et al., 1998; Terré et al., 2013) or a teat (Hammell et al., 1988; Veissier et al., 2002).

Some evidence indicates that motivation for nonnutritive oral behavior depends on satiety related to solid feed intake, and this may explain why providing forage reduces non-nutritive oral behaviors. Margerison et al. (2003) observed that calves decreased their nonnutritive oral behaviors around wk 3 of life when they increased concentrate and hay intake and the amount of time spent ruminating. Feeding and rumination time depend on the type of solid feed provided; Hodgson (1971), as cited by Kellaway et al. (1973a), found that calves spent 4 times longer per gram consuming hay than pelleted feed and 7 times longer ruminating hay than pellets. Phillips (2004) speculated that, because more fibrous feeds are slower to consume than concentrates, they may redirect suckling needs. This suggests that increasing feeding and rumination time by providing forage may help reduce non-nutritive oral behaviors. Interestingly, however, we observed that the duration devoted to non-nutritive oral behaviors increased over time in the present study, roughly doubling between wk 2 and wk 4. Thus, although forage provision may reduce non-nutritive behaviors, the increasing solid feed intake in this time frame did not coincide with a decrease in these behaviors, as observed by Margerison et al. (2003).

Considering the time that the TH calves spent sucking on the teat in combination with the amount of time spent performing non-nutritive sucking on pen fixtures, the duration of total sucking behavior was similar between treatments. This suggests that the teat acted as a preferred outlet for sucking (Ude et al., 2011), redirecting behavior from other pen fixtures. Although the total duration of sucking was similar between treat-

Table 4. Feed intake and growth performance of calves provided with milk via a bucket and no access to hay (CON), milk via a bucket and access to hay $(\mathrm{H})$, and milk via a teat and access to hay (TH) over the weaning transition (preweaning, weaning, and postweaning)

\begin{tabular}{|c|c|c|c|c|c|c|c|}
\hline Item & \multicolumn{3}{|c|}{ Treatment } & $\mathrm{SE}$ & \multicolumn{3}{|c|}{$P$-value ${ }^{1}$} \\
\hline$\overline{\mathrm{BW}}(\mathrm{kg})$ & 62.66 & 60.74 & 63.48 & 1.81 & 0.532 & $<0.0001$ & 0.057 \\
\hline Concentrate DMI (kg/d) & 0.824 & 0.667 & 0.697 & 0.094 & 0.83 & $<0.0001$ & 0.96 \\
\hline Hay DMI $(\mathrm{kg} / \mathrm{d})$ & - & 0.086 & 0.110 & 0.009 & 0.073 & $<0.0001$ & 0.753 \\
\hline Total DMI (kg/d) & 0.824 & 0.743 & 0.792 & 0.094 & 0.807 & $<0.0001$ & 0.407 \\
\hline
\end{tabular}

\footnotetext{
${ }^{a, b}$ Means within a row with different superscript letters indicate a significant difference $(P<0.05)$ between treatments.

${ }^{1} \mathrm{~T}=$ treatment $(\mathrm{CON}, \mathrm{H}, \mathrm{TH}) ; \mathrm{S}=$ stage of weaning transition (10 d preweaning, weaning, $10 \mathrm{~d}$ postweaning).
} 
ments when including time spent sucking on the teat, directed sucking toward a teat may be beneficial to calf welfare. This outlet is regularly cleaned and is made of a safe material for sucking, compared with potentially dirty pens or other calves in the case of group housing. However, the similar total duration of sucking between treatments does suggest that, in the case of restrictedfed calves, providing milk via a teat does little to satisfy a calf's motivation to suck.

We predicted that $\mathrm{TH}$ calves would consume less hay than $\mathrm{H}$ calves throughout the preweaning period, because both hay and a teat may function as outlets for oral behavior. Surprisingly, we found that hay intake evolved differently over time between $\mathrm{H}$ and $\mathrm{TH}$ calves (Figure 2b). However, we observed no corresponding difference in the amount of time spent consuming hay, because behavior observation days occurred when hay consumption was similar between treatments. Ude et al. (2011) reported that rubber teats are preferred over hay when calves have access to both hay and a teat immediately after a milk meal, although calves will select hay when a teat is not present (Haley et al., 1998). It is possible that the $\mathrm{H}$ calves consumed hay as an outlet for oral behaviors in early weeks, and the $\mathrm{TH}$ calves used their teat as an outlet for this behavior. At the time when TH calves increased the amount of hay consumed, around wk 4 of life (Figure 2b), H calves were increasing the amount of concentrate consumed (Figure 1) and hay intake plateaued briefly. Provision of a teat may then have some influence on the age at which calves begin to increase forage selection in their diet. The trend for $\mathrm{TH}$ calves to consume more hay than $\mathrm{H}$ calves continued across weaning, suggesting that the early life experience with hay may have shaped feeding preferences after weaning (Miller-Cushon et al., 2013b).

Several recent studies have evaluated the effects of forage provision before weaning on the behavior and performance of dairy calves. The effects of hay provision are likely to vary depending on several factors, including milk-feeding level (Khan et al., 2016) and forage type (Castells et al., 2012). However, several studies have reported performance benefits of providing forage, including greater total DMI, feed efficiency, and BW (Coverdale et al., 2004; Khan et al., 2011a), although the effects of forage provision on gut fill can complicate the interpretation of growth responses. In the present study, we found that forage provision did not positively or negatively affect BW, feed efficiency, or total DMI in the preweaning stage. However, we did find that calves provided with hay consumed less concentrate. It is possible that the effect of hay provision on concentrate intake could depend on the amount of hay provided - or selected - in the diet. Castells et al. (2012) reported that calves provided with alfalfa hay selected $8 \%$ of hay in their diet and had reduced concentrate intake. In comparison, calves in the same study had lower voluntary forage intake when provided with other forage sources (e.g., 3 to $6 \%$ of dietary intake of forage when calves were provided with rye grass hay, oat hay, and barley straw), and these lower forage intakes stimulated concentrate intake compared with calves that were not offered any forage source (Castells et al., 2012). Similarly, others have reported that provision of forage stimulates concentrate intake (Phillips, 2004). Castells et al. (2012) suggested that when the forage source is perceived as highly palatable, greater intake may offset concentrate intake. In the present study, calves consumed $16 \pm 8 \%$ of hay in their diet, on average, across the milk-feeding stage. This selection of forage was 2 to 5 times greater than the dietary proportion of hay in other studies (Coverdale et al., 2004; Castells et al., 2012) that reported a stimulating effect of hay provision on concentrate intake. As such, this high level of forage selection may have offset concentrate consumption. Some differences between studies may depend on the characteristics of solid feed provided. The hay provided in our study was similar in CP and NDF to Terré et al. (2013) and the rye hay and oat hay treatments in Castells et al. (2012), who noted that provision of these types of hay stimulated concentrate intake. The hay we provided was lower in CP than Khan et al. (2011a) and Coverdale et al. (2004), who reported greater total intakes in calves provided with hay. Anecdotally, we noted that calves in the present study preferentially consumed hay over concentrate at the time of fresh feed delivery, suggesting that the timothy hay was perceived as highly palatable. Consumption of hay appears to satisfy a behavioral need, but the effects on concentrate intake and growth require consideration when voluntary intake of hay is relatively high.

Calves in this study were all fed milk at a restricted level, because we focused on approaches to allow some aspects of natural feeding behavior in calves managed according to widespread conventional management (individual housing and restricted milk-feeding). It is likely that the results we have reported may depend on the milk-feeding program. Non-nutritive oral behaviors are reduced when more milk is provided (de Paula Vieira et al., 2008; de Passillé et al., 2010), and when the calf is allowed to suckle from the dam (Fröberg and Lidfors, 2009; Roth et al., 2009; Veissier et al., 2013). Milk-feeding level also influences solid feed intake and activity (Bach et al., 2013; Miller-Cushon et al., 2013a). Hay provision may reduce non-nutritive oral behaviors in calves managed on a moderately elevated milk-feeding level: Montoro et al. (2013) reported that, in calves fed $8 \mathrm{~L} / \mathrm{d}$ of milk replacer, the provision of 
coarsely chopped hay (compared with finely ground hay) reduced non-nutritive oral behaviors.

Across the weaning transition, we found that total DMI and concentrate DMI were similar between treatments, but ADG varied across treatments. Several studies have observed increased concentrate intake in calves provided with forage, either across all weaning stages (Kellaway et al., 1973b) or just at the postweaning stage (Terré et al., 2013). Limited amounts of roughage have also been shown to decrease ADG preweaning, but increase ADG and feed efficiency postweaning (Hill et al., 2008). In the present study, ADG in TH calves fell between $\mathrm{CON}$ and $\mathrm{H}$ calves and did not differ significantly from either, but the numerical improvement over $\mathrm{H}$ calves may relate to the tendency for greater hay intake during this period, whereas concentrate intake was similar between treatments. However, we measured postweaning growth over a short period and only compared BW, rather than other growth indicators (e.g., height and chest barrel diameter) that would provide a more complete comparison of postweaning growth.

Providing access to both a teat and hay during the milk-feeding stage decreased non-nutritive oral behaviors compared with providing milk by bucket and no access to hay. Calves provided with milk by bucket and access to hay had intermediate responses. Calves provided with a teat spent less time sucking on pen fixtures and redirected their sucking behavior to the teat. Selection of hay was influenced by milk-feeding method, and different effects were seen over time. In early weeks of the preweaning period, calves provided with a teat and hay consumed less hay than calves without a teat, but increased their hay intake in later weeks. These results suggest that the dietary selection of hay in early weeks of life may depend on alternative outlets for oral behavior. Further, these results suggest a cumulative effect of both hay and teat provision in reducing non-nutritive oral behavior.

\section{ACKNOWLEDGMENTS}

We thank the staff at the University of Florida Dairy Unit, as well as our undergraduate research studentsAmber DeWitt, Kelly Flanagan, James Gross, Rachel McKinnery, Taylor Pollak, Jessica Reynolds, and Kristen Solari-for their technical assistance. KH was supported by a Matching Assistantship through the Department of Animal Sciences, University of Florida.

\section{REFERENCES}

AOAC International. 2000. Official Methods of Analysis. Vol. I. 17th ed. AOAC International, Arlington, VA.
Babu, L. K., H. N. Pandey, and A. Sahoo. 2004. Effect of individual versus group rearing on ethological and physiological responses of crossbred calves. Appl. Anim. Behav. Sci. 87:177-191.

Bach, A., M. Terré, and A. Pinto. 2013. Performance and health responses of dairy calves offered different milk replacer allowances. J. Dairy Sci. 96:7790-7797.

Bokkers, E. A. M., and P. Koene. 2001. Activity, oral behaviour and slaughter data as welfare indicators in veal calves: A comparison of three housing systems. Appl. Anim. Behav. Sci. 75:1-15.

Bonk, S., O. Burfeind, V. S. Suthar, and W. Heuwieser. 2013. Technical note: Evaluation of data loggers for measuring lying behavior in dairy calves. J. Dairy Sci. 96:3265-3271.

Castells, L., A. Bach, G. Araujo, C. Montoro, and M. Terré. 2012 Effect of different forage sources on performance and feeding behavior of Holstein calves. J. Dairy Sci. 95:286-293.

Coverdale, J. A., H. D. Tyler, J. D. Quigley, and J. A. Brumm. 2004 Effect of various levels of forage and form of diet on rumen development and growth in calves. J. Dairy Sci. 87:2554-2562.

de Passillé, A. M. 2001. Sucking motivation and related problems in calves. Appl. Anim. Behav. Sci. 72:175-187.

de Passillé, A. M., B. Sweeney, and J. Rushen. 2010. Cross-sucking and gradual weaning of dairy calves. Appl. Anim. Behav. Sci. 124:11-15.

de Paula Vieira, A., V. Guesdon, A. M. de Passillé, M. A. G. von Keyserlingk, and D. M. Weary. 2008. Behavioural indicators of hunger in dairy calves. Appl. Anim. Behav. Sci. 109:180-189.

Friard, O., and M. Gamba. 2016. BORIS: A free, versatile open-source event-logging software for video/audio coding and live observations. Methods Ecol. Evol. 7:1335-1330.

Fröberg, S., and L. Lidfors. 2009. Behaviour of dairy calves suckling the dam in a barn with automatic milking or being fed milk substitute from an automatic feeder in a group pen. Appl. Anim. Behav. Sci. 117:150-158.

Haley, D. B., J. Rushen, I. J. Duncan, T. M. Widowski, and A. M. De Passillé. 1998. Effects of resistance to milk flow and the provision of hay on nonnutritive sucking by dairy calves. J. Dairy Sci. $81: 2165-2172$

Hammell, K. L., J. H. M. Metz, and P. Mekking. 1988. Sucking behaviour of dairy calves fed milk ad libitum by bucket or teat. Appl. Anim. Behav. Sci. 20:275-285.

Hill, T. M., H. G. Bateman, J. M. Aldrich, and R. L. Schlotterbeck. 2008. Effects of the amount of chopped hay or cottonseed hulls in a textured calf starter on young calf performance. J. Dairy Sci. 91:2684-2693.

Hodgson, J. 1971. The development of solid food intake in calves. 2. Studies on the volume of rumen fluid, determined by an indirect method. Anim. Prod. 12:25.

Jensen, M. B., and M. Budde. 2006. The effects of milk feeding method and group size on feeding behavior and cross-sucking in grouphoused dairy calves. J. Dairy Sci. 89:4778-4783.

Jensen, M. B., and D. Weary. 2013. Group housing and milk feeding of dairy calves. Adv. Dairy Technol. 25:179-189.

Jung, J., and L. Lidfors. 2001. Effects of amount of milk, milk flow and access to a rubber teat on cross-sucking and non-nutritive sucking in dairy calves. Appl. Anim. Behav. Sci. 72:201-213.

Kellaway, R. C., T. Grant, and J. W. Chudleigh. 1973a. The roughage requirement of early weaned calves. Aust. J. Exp. Agric. Anim. Husb. 13:9-12.

Kellaway, R. C., T. Grant, and J. W. Chudleigh. 1973b. The effect of roughage and buffers in the diet of early weaned calves. Aust. J. Exp. Agric. Anim. Husb. 13:225-228.

Khan, M. AWeary, D. M., and M. A. G. von Keyserlingk. 2011b. Invited review: Effects of milk ration on solid feed intake, weaning, and performance in dairy heifers. J. Dairy Sci. 94:1071-1081.

Khan, M. A., A. Bach, D. M. Weary, and M. A. G. von Keyserlingk. 2016. Invited review: Transitioning from milk to solid feed in dairy heifers. J. Dairy Sci. 99:885-902.

Khan, M. A., D. M. Weary, and M. A. G. von Keyserlingk. 2011a. Hay intake improves performance and rumen development of calves fed higher quantities of milk. J. Dairy Sci. 94:3547-3553. 
Lupoli, B., B. Johansson, K. Uvnäs-Moberg, and K. SvennerstenSjaunja. 2001. Effect of suckling on the release of oxytocin, prolactin, cortisol, gastrin, cholecystokinin, somatostatin and insulin in dairy cows and their calves. J. Dairy Res. 68:175-187.

Margerison, J. K., T. R. Preston, N. Berry, and C. J. C. Phillips. 2003. Cross-sucking and other oral behaviours in calves, and their relation to cow suckling and food provision. Appl. Anim. Behav. Sci. 80:277-286.

Miller-Cushon, E., and T. DeVries. 2015. Development and expression of dairy calf feeding behaviour. Can. J. Anim. Sci. 95:150511122835009.

Miller-Cushon, E. K., R. Bergeron, K. E. Leslie, and T. J. DeVries. 2013a. Effect of milk feeding level on development of feeding behavior in dairy calves. J. Dairy Sci. 96:551-564. https://doi. org/10.3168/jds.2012-5937.

Miller-Cushon, E. K., R. Bergeron, K. E. Leslie, G. J. Mason, and T. J. DeVries. 2013b. Effect of early exposure to mixed rations differing in forage particle size on feed sorting of dairy calves. J. Dairy Sci. 96:3257-3264.

Montoro, C., E. K. Miller-Cushon, T. J. DeVries, and A. Bach. 2013. Effect of physical form of forage on performance, feeding behavior, and digestibility of Holstein calves. J. Dairy Sci. 96:1117-1124.

Phillips, C. J. C. 2004. The effects of forage provision and group size on the behavior of calves. J. Dairy Sci. 87:1380-1388.
Roth, B. A., K. Barth, L. Gygax, and E. Hillmann. 2009. Influence of artificial vs. mother-bonded rearing on sucking behaviour, health and weight gain in calves. Appl. Anim. Behav. Sci. 119:143-150.

Terré, M., E. Pedrals, A. Dalmau, and A. Bach. 2013. What do preweaned and weaned calves need in the diet: A high fiber content or a forage source? J. Dairy Sci. 96:5217-5225.

Ude, G., H. Georg, and A. Schwalm. 2011. Reducing milk induced cross-sucking of group housed calves by an environmentally enriched post feeding area. Livest. Sci. 138:293-298.

Van Soest, P. J., J. B. Robertson, and B. A. Lewis. 1991. Methods for dietary fiber, neutral detergent fiber and non-starch polysaccharide in relation to animal nutrition. J. Dairy Sci. 74:3583-3597.

Veissier, I., S. Caré, and D. Pomiès. 2013. Suckling, weaning, and the development of oral behaviours in dairy calves. Appl. Anim. Behav. Sci. 147:11-18

Veissier, I., A.M. De Passillé, G. Després, J. Rushen, I. Charpentier, A. R. Ramirez de la Fe, and P. Pradel. 2002. Does nutritive and non-nutritive sucking reduce other oral behaviors and stimulate rest in calves? J. Anim. Sci. 80:2574-2587.

Veissier, I., A. R. Ramirez De La Fe, and P. Pradel. 1998. Nonnutritive oral activities and stress responses of veal calves in relation to feeding and housing conditions. Appl. Anim. Behav. Sci. 57:35-49. 